\title{
An investigation into the use of textual references to sunshine and fresh air in farm holiday advertising
}

\author{
Vincent P. Magnini \\ Longwood University, Farmville, Virginia, USA \\ Erika Quendler \\ Federal Institute of Agricultural Economics, Rural and Mountain Research, \\ Vienna, Austria, and \\ Muzaffer Uysal \\ University of Massachusetts, Amherst, Massachusetts, USA
}

\begin{abstract}
Purpose - Using the context of a farm holiday venue, the purpose of this study is to empirically test whether textual references can have significant influences on potential consumers' affective responses and interest in advertisements.

Design/methodology/approach - In a between-subjects experiment, a reference to sunshine (the underlined phrase in the following narrative) was inserted into a Facebook advertisement for a farm holiday venue: "Relax and Rejuvenate for a couple of days on our farm. Great food, fun, and sunshine ... See More".

Findings - Results indicate that a reference to sunshine significantly improves consumers' affective responses to the advertisement and significantly increases their interest (propensity to click "see more"). This study also examines the potential influence of a textual reference to fresh air as well as fresh air in combination with sunshine. No statistically significant results are found with the fresh air reference.

Originality/value - While a number of studies have examined text-based sensory details in marketing stimuli (Magnini and Gaskins, 2010; Torto, 2016), the notion of inserting textual references to fresh air and/or sunshine in advertising has not been empirically examined in the body of the existing literature.
\end{abstract}

Keywords Affective response to advertising, Advertising cues, Farm holiday, Fresh air, Sunshine

Paper type Research paper

\section{Introduction}

The global COVID-19 pandemic has increased consumer interest in nature-based attractions where one can relax and rejuvenate with an abundance of fresh air and sunshine. The question is therefore raised as to whether farm holiday venues should reinforce these important elements in the minds of potential visitors by inserting phrases containing textual references to sunshine or fresh air in their marketing? Would doing so enhance potential consumer interest in the ads?

While a number of studies have examined text-based sensory details in marketing stimuli (Magnini and Gaskins, 2010; Magnini and Karande, 2010; Torto, 2016), the notion of inserting textual references to fresh air and/or sunshine in advertising has not been empirically

(C) Vincent P. Magnini, Erika Quendler and Muzaffer Uysal. Published in International Hospitality Review. Published by Emerald Publishing Limited. This article is published under the Creative Commons Attribution (CC BY 4.0) licence. Anyone may reproduce, distribute, translate and create derivative works of this article (for both commercial and non-commercial purposes), subject to full attribution to the original publication and authors. The full terms of this licence may be seen at http:// creativecommons.org/licences/by/4.0/legalcode

Farm holiday advertising

Received 10 June 2021 Revised 25 August 2021 Accepted 25 August 2021

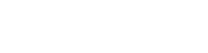


examined in our body of existing literature. Consequently, the purpose of this study is to empirically test whether such textual references can have significant influences on potential consumers' affective responses and interest in the ads. A between subjects factorial design experiment is employed for this purpose. The experiment uses the context of Facebook posts by farm holiday providers to test the hypotheses for two primary reasons. First, Facebook witnesses more than one billion active users each day (Banerjee and Chua, 2019). Second, the context of a farm holiday is used because this sector had been growing at a steady pace in many places around the globe pre-pandemic and is now experiencing accelerated growth due to the pandemic (Wojcieszak-Zbierska et al., 2020).

With this in mind, the literature review gives theoretical support for the hypotheses that textual references to sunshine and fresh air in an ad can have a significant influence on affective responses and interest. The literature review is followed by a section describing the research methods employed to conduct the experiment and the presentation of empirical results. This paper then concludes with a discussion of the implications and limitations of this study that might aid in prompting future research extensions.

\section{Literature review and hypothesis development}

The effects of a textual reference to sunshine

On a global level, an effective response can be conceptualized as an emotion, feeling, mood or evaluation with a range of potential intensity and arousal-levels (Peter and Olsen, 2002). With regard to responses to marketing stimuli, the specific dimensions of enjoyable, likeable, persuasive and interesting can encompass one's affective response (Peck and Wiggins, 2006; Zinkhan and Martin, 1983). Such positive affective responses to advertising have been demonstrated to be antecedents to a number of desirable outcomes such as purchase behavior (Teng et al., 2007) and loyalty (Ha et al., 2011).

Past studies have demonstrated that inserting certain textual sensory detail elements into advertisements can influence consumers' affective responses to the ads. For example, Magnini and Karande (2010) tested the effects of a textual reference to smell in a magazine ad for an ecotourism destination and found significant impacts on affective responses to the ad. In a different context, Magnini and Gaskins (2010) examined the influences of textual references to touch in outdoor destination advertisements and found positive significant influences on female's affective responses to the ads.

According to Torto (2016), textual sensory details in adverts can strengthen potential consumers' ability to imagine seeing, hearing, smelling, tasting and/or touching an advertised item. The primary objective of such "description in advertising is to frame an image of a product in the minds of the consumer ..." (Torto, 2016, p. 47). Within the context of tourism, if such advertising language is congruent with the traveler's motivation/travel goals, then positive affective responses can be triggered (Byun and Jang, 2015). Because one's motivation to visit a farm holiday venue is typically to experience a natural setting, such congruence exists with the use of a textual reference to sunshine. Along these lines, consumers are increasingly concerned with authenticity (Soligo and Abarbanel, 2020) and such natural elements are woven into the basic fabric of the farm holiday experience.

In fact, sunshine is a key ingredient in a natural setting such as a farm holiday venue where patrons retreat to be rejuvenated. Evidence of the influence of sunlight on mental well-being is contained, for example, in studies that demonstrate that the shortening length of the day can affect mental well-being (Partonen and Lönnqvist, 2000). Sunshine increases serotonin and vitamin D levels in humans. Many of the physical and mental benefits associated with sunlight intake are due to the body's circadian rhythm - an internal clock that monitors one's sleep-wake cycles (Rea et al., 2010). Hence, reinforcing the sunshine element through a textual reference to sunshine might strengthen potential 
consumers' affective responses to a farm holiday ad; consequently, the following hypothesis is offered:

H1. Using a textual reference to sunshine in a farm holiday advertisement will positively influence an individual's affective response to the ad.

Various advertising elements can induce purchase intentions and purchase behaviors (Alalwan, 2018; Saleem and Abideen, 2011). As seen in Figure 1, however, the messaging in this study's Facebook treatments was briefly followed by the invitation for the reader to click "see more." By using Facebook's postings design this study attempted to be as true to reality as possible. Given the brevity of the marketing stimuli, the propensity to click "see more" is a more realistic assessment of one's interest than asking about the likelihood of visiting the advertised farm venue with the presentation of only brief information. Stated differently, it seems logical that anyone interested in potentially visiting the venue after exposure to the abbreviated Facebook stimulus would click "see more" to learn more before making a decision to visit. In this context, clicking "see more" is a manifestation of interest in the advertised item. Therefore, the logic from the previous section is extended to predict that:

H2. Using a textual reference to sunshine in a farm holiday advertisement will positively influence an individual's interest in the ad.

\section{The effects of a textual reference to fresh air}

The same literature and empirical studies anchoring hypotheses 1 and 2 (predictions relating to the sunshine reference) also apply to the use of a textual reference to fresh air. That is, both sunshine and fresh air are critical natural elements engrained in the very fabric of the farm holiday experience.

While research related to fresh air often pertains to the treatment of illness (e.g. Hobday and Cason, 2009; Strange, 1991), it is prudent to recognize that fresh air has a host of benefits in healthy individuals as well. Nowadays, there is a wide range of exercises in fresh air, also called green exercises that generate health benefits. These activities include walking, cycling, horseback riding, woodland activities, fishing, etc. (Pretty et al., 2005, 2007). Such activities conducted in nature-based settings are known to improve physical (Gebhard, 2014;
Farm holiday advertising

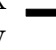

\author{
(1)
}


Sandifer et al., 2015), mental (Sandifer et al., 2015; Harshfield et al., 2019) and cognitive health (Berman et al., 2012; Stenfors et al., 2019).

In a recent peer-reviewed study titled "Fresh air, sunshine and happiness: Millennials building health (salutogenesis) in leisure and nature" Young et al. (2018, p. 331) asked a sample of undergraduate students to respond to the following two items:

(1) Please tell us three things that build up your health.

(2) Now, tell us how these things work for you to build up your health.

The theme of fresh air emerged in a number of the study's responses; for example (Young et al., 2018, p. 335):

Travelling and being outdoors - fresh air, adventures, freedom ...

Outdoors: provides fresh air, alone time and peacefulness

I love fresh air, the bit of fitness and the escape for a few hours every time I am out there

To reiterate, these discussions underscore the notion that the anchoring of hypotheses 1 and 2 also applies to the context of a textual reference to fresh air. Therefore, the following hypotheses are offered:

H3. Using a textual reference to fresh air in a farm holiday advertisement will positively influence an individual's affective response to the ad.

H4. Using a textual reference to fresh air in a farm holiday advertisement will positively influence an individual's interest in the ad.

\section{Research methods}

Design

A between-subjects factorial experiment was constructed to test the research hypotheses. In the experiment, subjects were randomly exposed to 1 of the 4 Facebook screenshots contained in Figure 1. As such, in this experiment, the manipulated variables were the textual reference to sunshine (present/absent/interaction with textual reference to fresh air) and the textual reference to fresh air (present/absent/interaction with textual reference to sunshine). As seen in Figure 1, other than the manipulated textual reference, all other details in the Facebook post such as number of shares and number of likes were kept constant because such factors can influence consumer sentiment (Mochon et al., 2017). As detailed next, all other variables (dependent variables and covariates) were measured as opposed to manipulated.

\section{Measurement of dependent variables}

Consumers' affective response to the advertisement: In concert with previous studies (Magnini and Karande, 2010; Peck and Wiggins, 2006; Zinkhan and Martin, 1983), consumers' affective responses to the advertisement were operationalized using four items: enjoyable, interesting, likeable and persuasive on 7-point Likert-type scales anchored with strongly disagree (1) and strongly agree (7). In this study, the four items demonstrated excellent reliability with a Cronbach's alpha of 0.9 (Nunnally and Bernstein, 1994). Therefore, the responses to the four items were averaged to derive a composite "affective response" score.

Consumers' interest in the advertisement: As seen above, consumers' interest in the Facebook advertisement was already captured by the affective response scale with the "interesting" scale item. Nevertheless, as an additional means of gaging a respondent's interest, the following item was included on the survey: "You might click "see more" ("strongly disagree" = 1; "strongly agree" = 7). 
Measurement of covariates

COVID-19 safety: Because the data were collected during the COVID-19 pandemic, the perceived risk associated with visiting the advertised farm holiday venue could influence the results of this study. Therefore, the following item was included as a covariate in the modeling: "This venue is probably safer from the risk of COVID-19 than many other travel destinations" ["strongly disagree" = 1; "strongly agree" = 7].

Consumers' gender. Because Facebook usage habits can be influenced by gender (Hoy and Milne, 2010; Thompson and Lougheed, 2012; Tifferet and Vilnai-Yavetz, 2014), respondents were asked to indicate their gender on the survey instrument.

Connectedness to nature. It is plausible that one's connectedness to nature could influence one's response to sunshine and/or fresh air references. Consequently, Mayer and Frantz's (2004) connectedness to nature scale was included in the survey (see Appendix). The 14 items exhibited excellent reliability with a Cronbach's alpha of 0.91 (Nunnally and Bernstein, 1994). Hence, the responses to the 14 items were averaged to derive a composite "connectedness score."

\section{Manipulation of independent variables}

Ad's sunshine reference: The ad's sunshine reference was either present or absent (See Figure 1).

Ad's fresh air reference: The ad's fresh air reference was either present or absent (See Figure 1).

Interaction effect: Potential interaction was tested with a treatment that contained both a sunshine reference and a fresh air reference (see Figure 1).

\section{Pretest: suitability of treatment conditions and experimental realism}

In concert with experimental design guidelines recommended by Perdue and Summers (1986), a convenience sample of 18 respondents pretested the survey. The purpose of this pretest was to help ensure that it be possible to manipulate the treatment conditions as intended while also retaining experimental realism. In terms of manipulations, if the overall look and feel of the experimental Facebook post (See Figure 1) produced results on the dependent measures (affective response and intent) that were overly negative or overly positive regardless of the presence or absence of the sunshine/fresh air reference then that overall look/feel could potentially mask any effects of the sunshine/fresh air reference(s). Pretest results confirmed that the experimental manipulations could be perceived as intended because the dependent variables (DVs) across the four posting conditions in the pretest produced mid-range sentiment: affective response $=4.43(\mathrm{SD}=1.66)$ and interest $=4.89(\mathrm{SD}=1.9)$.

Regarding a check of experimental realism, participants were asked to respond to this item: "The screenshot of the Facebook post looks like a real Facebook post" anchored with strongly disagree (1) and strongly agree (7). Pretest results confirmed adequate realism of the Facebook post used in this experiment: realism $=5.41(\mathrm{SD}=1.18)$.

\section{Main study procedures}

The data were collected throughout the United States by placing an online survey on Amazon's MTurk consumer panel. To help ensure the quality of the collected data, only MTurk's master-level respondents were invited to participate [1]. Other than the need to be a master-level respondent, the need to be at least 18 years of age (which is already built into the MTurk panel), no other participation criteria were issued.

Data collection was carried out over a two week period spanning late October and early November 2020. Those responding to the survey invitation were randomly exposed to one of
Farm holiday advertising

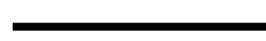


the four Facebook screenshots contained in Figure 1 followed by the survey questions. A total of 243 responses were initially collected. Two data quality screening procedures reduced the total useable sample size to 214 . Specifically, 22 sub-par responses were removed due to poor performance on the reverse-coded questions in the connectedness to nature scale; and 7 responses were removed of those who disagreed that the Facebook post looked real. The final cell sizes for each experimental treatment are listed in Table 1.

Of the respondents, $42 \%$ were female. The two largest age cohorts were $26-35$ years ( $32 \%)$ and 36-45 years (31\%). The most frequently reported Facebook usage rate was once per day $(26 \%)$ followed by $2-3$ times per week $(19 \%)$. While two respondents $(<1 \%)$ indicated that they never use Facebook, the results of the hypothesis testing reported in this study remain unchanged with/without these respondents.

\section{Results}

To test hypotheses 1 and 2, a multivariate analysis-of-covariance (MANCOVA) model was calculated. In the MANCOVA model, the independent variable (IV) was the sunshine reference (present vs. absent). As described in the previous section, covariates in the model were gender, perceived COVID-19 safety and connectedness to nature. The two dependent variables (DVs) in the model were affective response and interest. It is prudent to note that this MANCOVA model satisfied all of the assumptions necessary to perform such analysis. For instance, the IV was categorical, and the DVs were interval. Second, there were more observations than DVs in the experimental cells with no outliers. Third, the assumption of homoscedasticity was satisfied.

Hypotheses 1 and 2 predict that using a textual reference to sunshine in a farm holiday advertisement positively influences an individual's affective response to the ad (H1) and interest (H2). As indicated in Table 2, MANCOVA results (Wilks' Lambda $=0.945$, $F_{(2,103)}=2.90, p=0.06$, partial $\left.\eta^{2}=0.055\right)$ demonstrate statistically significant effects of the sunshine reference on affective response $\left(F_{(1.104)}=3.634, p=0.059\right.$, partial $\left.\eta^{2}=0.035\right)$ and interest $\left(F_{(1.104)}=5.464, p=0.021\right.$, partial $\left.\eta^{2}=0.052\right)$. Therefore, $\mathbf{H} 1$ and $\mathbf{H} 2$ are supported.

To test hypotheses 3 and 4, a second MANCOVA model was calculated. In the MANCOVA model, the IV was the fresh air reference (present vs. absent). As described in the previous section, covariates in the model were gender, perceived COVID-19 safety and connectedness to nature. The two DVs in the model were affective response and interest. Like the previously described MANCOVA, this model also satisfied all of the assumptions necessary to adequately perform the analysis.

Hypotheses 3 and 4 predict that using a textual reference to fresh air in a farm holiday advertisement positively influences an individual's affective response to the ad (H3) and interest (H4). As depicted in Table 3, MANCOVA results (Wilks' Lambda $=0.99$, $F_{(2.104)}=0.063, p=0.939$, partial $\left.\eta^{2}=0.001\right)$ do not reveal statistically significant effects of the fresh air reference on affective response $\left(F_{(1.105)}=0.124, p=0.726\right.$, partial $\left.\eta^{2}=0.001\right)$ or interest $\left(F_{(1.105)}=0.084, p=0.772\right.$, partial $\left.\eta^{2}=0.001\right)$. Therefore, $\mathrm{H} 3$ and $\mathrm{H} 4$ are not supported.

Table 1.

Cell sizes of treatment conditions
Treatment condition

Both textual references - absent

Textual sunshine reference - present

Textual fresh air reference - present

Both textual references - present
Cell size 


\begin{tabular}{|c|c|c|c|c|c|}
\hline Variables & $F$-value & Significance & Effect size & & Farm holiday \\
\hline \multicolumn{5}{|c|}{ Predicting affective response (H1) } & \\
\hline Sunshine & 3.63 & 0.059 & 0.035 & $\begin{array}{l}M_{\text {Absent }}=4.96, \mathrm{SD}=1.43 ; M_{\text {Present }}=5.30 \\
\mathrm{SD}=0.98\end{array}$ & \\
\hline Gender & 9.55 & 0.003 & 0.087 & & \\
\hline COVID-19 safety & 16.72 & 0.000 & 0.059 & & \\
\hline $\begin{array}{l}\text { Connectedness to } \\
\text { nature }\end{array}$ & 5.48 & 0.021 & 0.052 & & \\
\hline \multicolumn{6}{|l|}{ Predicting interest (H2) } \\
\hline Sunshine & 5.46 & 0.021 & 0.052 & $\begin{array}{l}M_{\text {Absent }}=5.06, \mathrm{SD}=1.79 ; M_{\text {Present }}=5.67 \\
\mathrm{SD}=1.34\end{array}$ & \\
\hline Gender & 6.32 & 0.014 & 0.059 & & \\
\hline COVID-19 safety & 10.75 & 0.001 & 0.097 & & Table 2. \\
\hline $\begin{array}{l}\text { Connectedness to } \\
\text { nature }\end{array}$ & 13.63 & 0.000 & 0.120 & & $\begin{array}{l}\text { MANCOVA results: } \\
\text { sunshine hypotheses }\end{array}$ \\
\hline
\end{tabular}

\begin{tabular}{|c|c|c|c|c|c|}
\hline Variables & $F$-value & Significance & Effect size & & \\
\hline \multicolumn{6}{|c|}{ Predicting affective response (H3) } \\
\hline Fresh air & 0.124 & 0.726 & 0.001 & $\begin{array}{l}M_{\text {Absent }}=4.96, \mathrm{SD}=1.43 ; M_{\text {Present }}=4.87 \\
\mathrm{SD}=1.25\end{array}$ & \\
\hline Gender & 6.41 & 0.001 & 0.104 & & \\
\hline COVID-19 safety & 13.13 & 0.000 & 0.112 & & \\
\hline $\begin{array}{l}\text { Connectedness to } \\
\text { nature }\end{array}$ & 20.48 & 0.000 & 0.164 & & \\
\hline \multicolumn{6}{|l|}{ Predicting interest (H4) } \\
\hline Fresh air & 0.084 & 0.772 & 0.001 & $\begin{array}{l}M_{\mathrm{Absent}}=5.06, \mathrm{SD}=1.79 ; M_{\text {Present }}=4.95 \\
\mathrm{SD}=1.84\end{array}$ & \\
\hline Gender & 6.41 & 0.013 & 0.058 & & \\
\hline COVID-19 safety & 4.00 & 0.048 & 0.037 & & Table 3. \\
\hline $\begin{array}{l}\text { Connectedness to } \\
\text { nature }\end{array}$ & 2.33 & 0.000 & 0.183 & & $\begin{array}{l}\text { MANCOVA results: } \\
\text { Fresh air hypotheses }\end{array}$ \\
\hline
\end{tabular}

As previously explained, even though it was not hypothesized, potential interaction effects between the sunshine reference and fresh air reference were also examined. The posting with both elements absent produced an effective response of 4.96 in comparison to 4.84 with both elements present. In terms of the ad's ability to generate interest, the condition with both elements absent generated an interest level of 5.06; whereas, the condition with both present garnered an interest level of 5.13. Neither of these mean differences is statistically significant. As such, it appears that the presence of the fresh air reference nullifies the statistically significant findings found when testing the stand-alone sunshine reference.

\section{Conclusions and implications}

From a research perspective, the results of this study provide several contributions to our existing knowledge. While there are multiple dimensions in potential visitors' cognitive image of rural destinations (Peña et al., 2012), this study examines how textual elements of ads can influence potential visitors' perceptions. This study, therefore, extends the body of 
research that explores the use of text-based sensory details in marketing stimuli (Magnini and Gaskins, 2010; Magnini and Karande, 2010; Torto, 2016). Similarly, this research makes a modest contribution to the body of literature that examines the important roles of fresh air and sunshine to both one's physical and mental well-being (Harshfield et al., 2019; Young et al., 2018).

The findings of this study are important not only to extend the theoretical knowledge of sensory detail elements in advertising, but also because they have practical value for those marketing nature-based attractions such as farm holiday venues. Table 4 provides an example from an Austrian network of farm holiday providers: less than 1,000 Facebook fans in 2010 and more than 41,000 in 2020. Therefore, any research that addresses how to increase affective responses and interest in Facebook posts appears to be highly germane to the industry. It is prudent to note that an important feature associated with the use of textual references in Facebook advertising is that the marketing tactic does not cost any money - in comparison to running a Facebook campaign without such textual references.

With regard to limitations, as with all experimental designs conducted in the social sciences, the findings and accompanying interpretations are limited by the nature of the stimuli, respondents and instruments. Therefore, there are a number of future research extensions possible in this area of inquiry. It would be informative to investigate, for example, whether a textual fresh air reference would produce significant results if nested within a different advertising context; for instance: for a park, nature preserve, or mountain resort/spa as opposed to a holiday farm venue. Specifically, perhaps the fact that some olfactory cues associated with a working farm have undesirable smells could have nullified the potential effect of the textual fresh air reference in the current study. Stated differently, the image of fresh or pure air might not be readily associated by some potential guests with farm tourism settings. As such, the testing of textual fresh air references in other naturebased settings is ripe for exploration. Similarly, Cetron et al. (2020, p. 130) indicate that "people around the world are increasingly sensitive to environmental issues such as air

Table 4.

Growth of Facebook presence in the farm holiday sector (Austrian example)
Farm Holiday Facebook Fans:

2010-2020

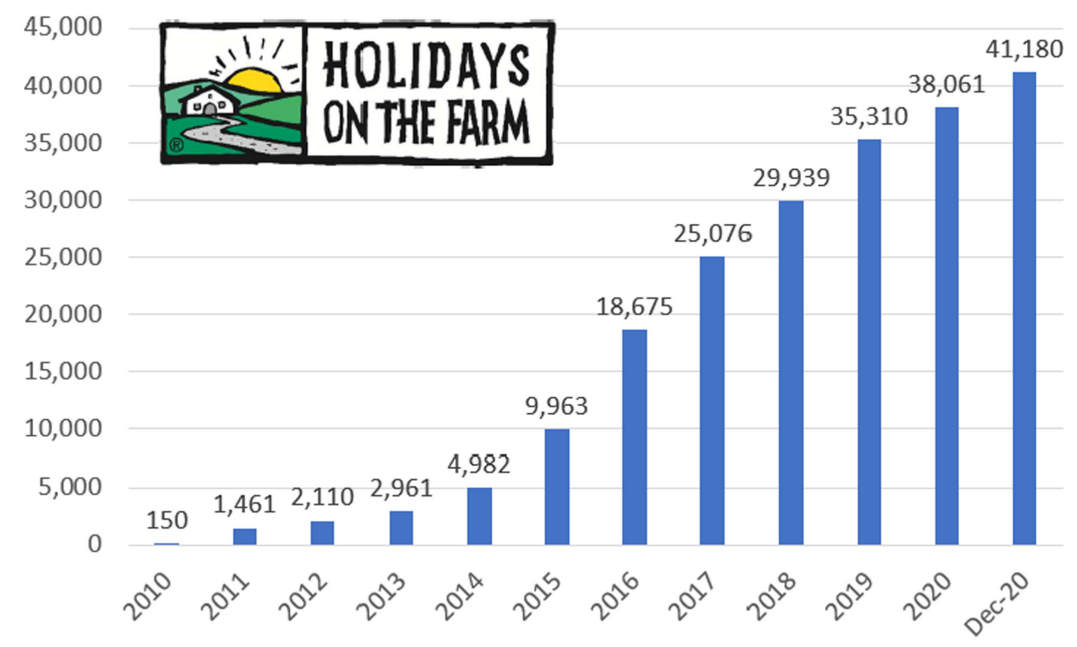

Source(s): Lackinger, 2020 
pollution ..." Therefore, future research should consider examining whether this increasing sensitivity might make consumers more responsive to textual fresh air references through time.

The effect sizes reported in this study are not large. Modest effect sizes are not an uncommon phenomenon in the study of grounded cognition (Juhasz et al., 2011) or in the service literature (De Matos et al., 2007; Magnini and Kim, 2016). Fritz et al. (2012) posit that observed effects in most experimental research in the service sciences are prone to be modest or even small. Interestingly, in this current study, the main effects of the reference to sunshine demonstrated larger effect sizes on both DVs when the models were calculated in the absence of the connectedness to nature covariate. Because there is theoretical justification for including this covariate, the models were calculated with its inclusion.

The current study purposefully collected data across a two-week period and from every region of the USA to circumvent any potentially heightened effects of the textual references as a result of respondents participating in the study during or following a day of rainy or cloudy weather. Nevertheless, future research extensions might consider testing the textual references in all four seasons and in areas of the world with particularly short/long daylight hours. In a similar vein, it would be interesting to investigate the strength of the textual reference influences after the pandemic has receded or come to a close. Because COVID-19 safety was controlled for in these research models as a covariate, it is thought that the significant findings reported in the current study are not driven solely by the pandemic conditions but are instead effects that can be harnessed by nature-based venue marketers across time, but further research would be prudent.

Lastly, much work remains to be done with regard to examining the influences of sunshine and fresh air references as components of marketing stimuli. For instance, while the current study examined textual references, there are evidently other ways by which these elements can be infused into marketing. Therefore, future research should extend this current work beyond textual references to examine graphics-based and verbal-based elements in advertisements for nature-based attractions.

\section{Note}

1. This master's qualification is earned by MTurk panel members by demonstrating a high degree of data quality in past projects. More detail about master's qualifications can be found here: https:// www.mturk.com/worker/help (accessed December 20, 2020). Restricting data collection to masterlevel respondents is significantly more costly than not doing so because a premium price is paid for master-level responses.

\section{References}

Alalwan, A. (2018), "Investigating the impact of social media advertising features on customer purchase intention”, International Journal of Information Management, Vol. 42, pp. 65-77.

Banerjee, S. and Chua, A.Y. (2019), "Identifying the antecedents of posts' popularity on Facebook fan pages", Journal of Brand Management, Vol. 26 No. 6, pp. 621-633.

Berman, M.G., Kross, E., Krpan, K.M., Askren, M.K., Burson, A., Deldin, P.J., Kaplan, S., Sherdell, L., Gotlib, I.H. and Jonides, J. (2012), "Interacting with nature improves cognition and affect for individuals with depression", Journal of Affective Disorder, Vol. 140, pp. 300-305.

Byun, J. and Jang, S.S. (2015), "Effective destination advertising: matching effect between advertising language and destination type", Tourism Management, Vol. 50, pp. 31-40.

Cetron, M.J., Davies, O., DeMicco, F. and Song, M. (2020), "Shaping the future of hospitality and travel: trends in energy, environmental, and labor force and work", International Hospitality Review, Vol. 34 No. 2, pp. 129-152.
Farm holiday advertising

$\longrightarrow$


De Matos, C.A., Henrique, J.L. and Rossi, C.A.V. (2007), "Service recovery paradox: a meta-analysis", Journal of Service Research, Vol. 10 No. 1, pp. 60-77.

Fritz, C.O., Morris, P.E. and Richler, J.J. (2012), "Effect size estimates: current use, calculations, and interpretation", Journal of Experimental Psychology: General, Vol. 141 No. 1, p. 2.

Gebhard, U. (2014), "Wie viel Natur 'braucht der Mensch? Natur' als Erfahrungsraum und Sinninstanz", Hartung, Gerald und Thomas Kirchhoff (Hrsg.): Welche Natur brauchen wir? Analyse einer anthropologischen Grundproblematik des 21. Jahrhunderts, Freiburg u. a.: Alber, pp. 249-274, available at: https://mobil.wwf.de/fileadmin/fm-wwf/Publikationen-PDF/TagungNatur-verbindet-Bielefeld-Ulrich-Gebhard-Wie-viel-Natur-braucht-der-Mensch.pdf.

Ha, H.Y., John, J., Janda, S. and Muthaly, S. (2011), "The effects of advertising spending on brand loyalty in services", European Journal of Marketing, Vol. 45 No. 4, pp. 673-691.

Harshfield, A., Manville, C., Elmore, N., Smith, P., Rodriguez Rincon, D., Hood, C. and Gehrt, D. (2019), A Scoping Study on the Link between Exposure to or Interaction with the Natural Environment and Mental Health Outcomes, RAND Corporation, Santa Monica, Calif., and Cambridge, available at: https://www.rand.org/pubs/research_reports/RR3122.html.

Hobday, R.A. and Cason, J.W. (2009), "The open-air treatment of pandemic influenza", American Journal of Public Health, Vol. 99 No. S2, pp. S236-S242.

Hoy, M.G. and Milne, G. (2010), "Gender differences in privacy-related measures for Young adult Facebook users", Journal of Interactive Advertising, Vol. 10 No. 2, pp. 28-45.

Juhasz, B.J., Yap, M.J., Dicke, J., Taylor, S.C. and Gullick, M.M. (2011), "Tangible words are recognized faster: the grounding of meaning in sensory and perceptual systems", Quarterly Journal of Experimental Psychology, Vol. 64 No. 9, pp. 1683-1691.

Lackinger, M. (2020), Urlaub am Bauernhof Österreich (English translation: Holidays on the Farm in Austria), available at: https:/www.urlaubambauernhof.at/.

Magnini, V. and Gaskins, J. (2010), "Gender differences in responses to written touch references in hospitality print advertisements", Tourism Analysis, Vol. 15 No. 3, pp. 331-343.

Magnini, V. and Karande, K. (2010), "An experimental investigation into the use of written smell references in ecotourism advertisements", Journal of Hospitality and Tourism Research, Vol. 34 No. 3, pp. 279-293.

Magnini, V. and Kim, S. (2016), "The influences of restaurant menu font style, background color, and physical weight on consumers' perceptions", International Journal of Hospitality Management, Vol. 53, pp. 42-48.

Mayer, F.S. and Frantz, C.M. (2004), "The connectedness to nature scale: a measure of individuals' feeling in community with nature", Journal of Environmental Psychology, Vol. 24 No. 4, pp. 503-515.

Mochon, D., Johnson, K., Schwartz, J. and Ariely, D. (2017), "What are likes worth? A Facebook page field experiment”, Journal of Marketing Research, Vol. 54 No. 2, pp. 306-317.

Nunnally, J. and Bernstein, I. (1994), Psychometric Theory, McGraw-Hill/Irwin, Boston.

Partonen, T. and Lönnqvist, J. (2000), "Bright light improves vitality and alleviates distress in healthy people", Journal of Affective Disorders, Vol. 57 Nos 1-3, pp. 55-61.

Peck, J. and Wiggins, J. (2006), "It just feels good: customers' affective response to touch and its influence on persuasion”, Journal of Marketing, Vol. 70 No. 4, pp. 56-69.

Peña, A.I.P., Jamilena, D.M.F. and Molina, M.Á.R. (2012), "Validation of cognitive image dimensions for rural tourist destinations: a contribution to the management of rural tourist destinations", Journal of Vacation Marketing, Vol. 18 No. 4, pp. 261-273.

Perdue, B.C. and Summers, J.O. (1986), "Checking the success of manipulations in marketing experiments", Journal of Marketing Research, Vol. 23 No. 4, pp. 317-326.

Peter, J. and Olsen, J. (2002), Consumer Behavior and Marketing Strategy, 6th ed., McGraw-Hill/Irwin, Boston. 
Pretty, J., Peacock, J., Sellens, M. and Griffin, M. (2005), “The mental and physical health outcomes of green exercise”, International Journal of Environmental Health Research, Vol. 15, pp. 319-337.

Pretty, J., Peacock, J., Hine, R., Sellens, M., South, N. and Griffin, M. (2007), "Green exercise in the UK countryside: effects on health and psychological well-being and implications for policy and planning", Journal of Environmental Planning and Management, Vol. 50, pp. 211-231, doi: 10. 1080/09640560601156466.

Rea, M.S., Figueiro, M.G., Bierman, A. and Bullough, J.D. (2010), “Circadian light”, Journal of Circadian Rhythms, Vol. 8 No. 1, p. 2.

Saleem, S. and Abideen, Z. (2011), "Effective advertising and its influence on consumer buying behavior", European Journal of Business and Management, Vol. 3 No. 3, pp. 55-67.

Sandifer, P.A., Sutton-Grier, A.E. and Ward, B.P. (2015), "Exploring connections among nature, biodiversity, ecosystem services, and human health and well-being: opportunities to enhance health and biodiversity conversation", Ecosystem Services, Vol. 12, pp. 1-15.

Soligo, M. and Abarbanel, B. (2020), "Theme and authenticity: experiencing heritage at the Venetian", International Hospitality Review, Vol. 34 No. 2, pp. 153-172.

Stenfors, C.U.D., van Hedger, S.C., Schwertz, K.E., Meyer, F.A., Smith, K.E.L., Norman, G.L., Bourrier, S.C., Enns, J.T., Kardan, O., Jonides, J. and Berman, M.G. (2019), "Positive effects of nature on cognitive performance across multiple experiments: test order but not affect modulates the cognitive effects", Frontiers in Psychology, Vol. 10, pp. 1-21, 1413.

Strange, F.G. (1991), The History of the Royal Sea Bathing Hospital, Margate, 1791-1991, Meresborough Books, Warszawa.

Teng, L., Laroche, M. and Zhu, H. (2007), "The effects of multiple-ads and multiple-brands on consumer attitude and purchase behavior”, Journal of Consumer Marketing, Vol. 24 No. 1, pp. 27-35.

Thompson, S.H. and Lougheed, E. (2012), "Frazzled by Facebook? An exploratory study of gender differences in social network communication among undergraduate men and women", College Student Journal, Vol. 46, p. 1.

Tifferet, S. and Vilnai-Yavetz, I. (2014), "Gender differences in Facebook self-presentation: an international randomized study”, Computers in Human Behavior, Vol. 35, pp. 388-399.

Torto, R.T. (2016), "An analysis of descriptive features in the English used in an advertising text", International Journal of Linguistics, Vol. 4 No. 2, pp. 47-55.

Wojcieszak-Zbierska, M.M., Jẹczmyk, A., Zawadka, J. and Uglis, J. (2020), "Agritourism in the era of the coronavirus (COVID-19): a rapid assessment from Poland", Agriculture, Vol. 10, p. 397, available at: https://www.mdpi.com/2077-0472/10/9/397 (accessed 9 December 2020).

Young, J., McGrath, R. and Adams, C. (2018), "Fresh air, sunshine and happiness: millennials building health (salutogenesis) in leisure and nature", Annals of Leisure Research, Vol. 21 No. 3, pp. 324-346.

Zinkhan, G. and Martin, C. Jr (1983), "Message characteristics and audience characteristics: predictors of advertising response", in Bagozzi, R. and Tybout, A. (Eds), Advances in Consumer Research, Association for Consumer Research, Provo, UT, Vol. 10, pp. 27-31.
Farm holiday advertising 


\section{IHR}

\section{Appendix}

Mayer and Frantz's (2004) connectedness to nature scale.

You often feel a sense of oneness with the natural world around you.

You think of the natural world as a community to which you belong.

You recognize and appreciate the intelligence of other living organisms.

You often feel disconnected with nature (reverse coded).

When you think of your life, you imagine yourself to be part of a larger cyclical process of living.

You often feel a kinship with animals and plants.

You feel as if you belong to the Earth as equally as it belongs to you.

You have a deep understanding of how your actions affect the natural world.

You often feel part of the web of life.

You feel that all inhabitants of Earth, humans and nonhumans, share a common "life force".

Like a tree can be part of a forest, you feel embedded within a broader natural world.

When you think of your place on Earth, you consider yourself to be a top member of a hierarchy that exists in nature (reverse coded).

You often feel like you are only a small part of the natural world around you, and that you are no more important than the grass on the ground or the birds in the trees.

Your personal welfare is independent of the welfare of the natural world (reverse coded).

\section{Corresponding author}

Vincent P. Magnini can be contacted at: magniniVP@1ongwood.edu

For instructions on how to order reprints of this article, please visit our website: 